\title{
FACTORS INFLUENCING ENGINEERING STUDENTS' DECISIONS TO CHEAT BY TYPE OF ASSESSMENT
}

\author{
Honor J. Passow, ${ }^{*}$ Matthew J. Mayhew, ${ }^{* *}$ Cynthia J. Finelli, ${ }^{* * *,} \S$ \\ Trevor S. Harding, $†$ and Donald D. Carpenter $\ddagger$
}

Academic dishonesty (cheating) has been prevalent on college campuses for decades, and the percentage of students reporting cheating varies by college major. This study, based on a survey of 643 undergraduate engineering majors at 11 institutions, used two parallel hierarchical multiple regression analyses to predict the frequency of cheating on exams and the frequency of cheating on homework based on eight blocks of independent variables: demographics, pre-college cheating behavior, co-curricular participation, plus five blocks organized around Ajzen's Theory of Planned Behavior (moral obligation not to cheat, attitudes about cheating, evaluation of the costs and benefits of cheating, perceived social pressures to cheat or not to cheat, and perceived effectiveness of academic dishonesty policies). The final models significantly predict $36 \%$ of the variance in "frequency of cheating on exams" and $14 \%$ of the variance in "frequency of cheating on homework". Students don't see cheating as a single construct and their decisions to cheat or not to cheat are influenced differently depending on the type of assessment. Secondary findings are that a student's conviction that cheating is wrong no matter what the circumstances is a strong deterrent to cheating across types of assessment and that a student who agrees that he/she would cheat in order to alleviate stressful situations is more likely to cheat on both exams and homework.

KEY WORDS: cheating; examinations; homework; theory of planned behavior; engineering; higher education.

*Center for the Study of Higher and Postsecondary Education, University of Michigan, Ann Arbor, MI 48109, USA.

**Department of Student Life Assessment, University of North Carolina Wilmington, Wilmington, NC 28403, USA.

***College of Engineering and Center for Research on Learning and Teaching, University of Michigan, Ann Arbor, MI 48109, USA.

$\dagger$ Manufacturing Engineering, Kettering University, Flint, MI 48504, USA.

\$Civil Engineering, Lawrence Technological University, Southfield, MI 48075, USA.

§Address correspondence to: Cynthia J. Finelli, 1071 Palmer Commons, 100 Washtenaw Avenue, Ann Arbor, MI 48109, USA. E-mail: cfinelli@umich.edu 


\section{INTRODUCTION}

Academic dishonesty, or cheating, is widespread on college campuses throughout the United States (McCabe and Drinan, 1999). Reported percentages vary widely, although the percentages remained consistent over 30 years in the only known replication study. In 1993, McCabe worked with Bowers to resurvey nine of the schools that Bowers had surveyed in 1963. Although Bowers received responses from 5422 students at 99 institutions, the subset of these at the nine schools that McCabe resurveyed consisted of 452 responses (D.L. McCabe, personal communication, April 1, 2002). This study, replicated over time, indicates that the percentage of undergraduates self-reporting engagement in various cheating behaviors during college has not changed substantially from Bower's 1963 survey ( $82 \%$ of 452 respondents) to McCabe and Trevino's 1993 survey (84\% of 1793 respondents) (McCabe, 1997). The steady percentage of self-reported cheating has been substantiated by a meta-analysis (Brown and Emmett, 2001) and an additional study (Spiller and Crown, 1995). However, the severity of the cheating has increased substantially. McCabe (1997) offers examples:

For example, students admitting to copying from another student on an examination doubled from $26 \%$ to $52 \%$ between 1963 and 1993. Instances of helping someone else cheat on an examination and the use of crib notes each increased more than $50 \%$. McCabe and Trevino also observed a four-fold increase (from $11 \%$ to $49 \%$ ) in the number of students who admitted they had collaborated on assignments when the instructor had specifically asked for individual work. (p. 435)

Ten studies indicate that the percentage of undergraduates reporting engagement in various cheating behaviors differs by college major (Baird, 1980; Bowers, 1964; Brown, 1996; Harp and Taietz, 1966; Jackson, Levine, Furnham, and Burr, 2002; McCabe, 1997; Newstead, Franklyn-Stokes, and Armstead, 1996; Rawwas and Isakson, 2000; Roberts, Anderson, and Yanish, 1997; Shaughnessy, 1988). The findings are consistent: percentages of undergraduates reporting cheating are highest for those enrolled in "vocationally oriented majors such as business and engineering" (McCabe, 1997, p. 444), where business majors report the highest levels. McCabe collected survey data from 1,946 undergraduates at 16 highly selective institutions in 1995-1996, including questions about engagement during college in five different cheating behaviors on examinations, four different cheating behaviors on writing assignments, plus collaboration with other students on assignments when the instructor wanted individual work. Percentages of students reporting any type of cheating on the survey differed significantly 
$(p<.05)$ by college major: business $(91 \%)$, engineering $(82 \%)$, social sciences $(73 \%)$, and natural sciences $(71 \%)$.

The prevalence and increasing severity of cheating should be distressing to educators because of their implications. First, most U.S. colleges and universities have a mission that includes preparation for citizenship, character development, moral leadership, and/or service to society; each of these has a moral dimension (King and Mayhew, 2002; Whitley and Keith-Spiegel, 2002). Prevalent undergraduate cheating undermines efforts to accomplish such missions. Also, in professions such as engineering, there is a growing, nationwide emphasis on graduating students who understand professional and ethical responsibility (Stark and Lattucca, 1997). Prevalent academic dishonesty indicates that many students will approach learning experiences in professional ethics with attitudes and habits that may interfere with their learning. Thus, interventions that effectively encourage a student not to cheat during college could help institutions fulfill their missions.

Second, acts of academic dishonesty undermine the validity of measures of student learning. This, in turn, interferes with faculty's ability to correctly diagnose gaps in student learning for the purpose of both re-teaching current students and re-designing instruction for future students. Whitley and Keith-Spiegel (2002) make related claims that cheating undermines equity in grading and the mission to transfer knowledge. Third, there are several costs to the entire educational enterprise that result from high levels of cheating. Student and faculty morale, the reputation of the institution, and public confidence in higher education are all damaged by rampant cheating, especially when it is ignored by faculty and administrators (Whitley and Keith-Spiegel, 2002). Any interventions that effectively encourage a student not to cheat during college could increase the validity of measures of student learning and also reduce damage to morale, institutional reputations, and public confidence in higher education.

Fourth, research has shown that students who cheat in college are more likely to cheat in graduate and professional schooling (Baldwin, Daugherty, Rowley, and Schwartz, 1996), to engage in unethical workplace behavior (Harding, Carpenter, Finelli, and Passow, 2003, 2004; Hilbert, 1985; Nonis and Swift, 2001; Ogilby, 1995; Sims, 1993; ToddMancillas, 1987), to shoplift (Beck and Ajzen, 1991), to cheat on income taxes (Fass, 1990), and to abuse substances (Blankenship and Whitley, 2000; Kerkvliet, 1994). For college graduates whose workplace had a strong corporate code of ethics, employees whose undergraduate school had an honor code were less likely than graduates of non-code schools to report engaging in unethical workplace behavior (McCabe, Trevino, 
and Butterfield, 1996). Note that much lower rates of cheating are reported by students at honor code schools (McCabe and Trevino, 1993). All of these correlations, though not known to be causal, raise the possibility that interventions that effectively encourage a student not to cheat during college could reduce the frequency of his or her decisions to engage in other unethical behavior during college and beyond.

These four implications of the prevalence and severity of cheating have inspired a substantial body of research on cheating among college students. Eleven reviews (including three meta-analyses) of college cheating behavior have been published since 1977 (Brown and Emmett, 2001; Bushway and Nash, 1977; Cizek, 1999; Cole and McCabe, 1996; Crown and Spiller, 1998; Dowd, 1992; Kibler, 1993; McCabe, Trevino, and Butterfield, 2001; Whitley, 1998; Whitley and Keith-Spiegel, 2002; Whitley, Nelson, and Jones, 1999). There are three veins of published studies, addressing three different overarching goals: (1) documenting the prevalence of college student cheating to establish the importance of the problem, (2) understanding the factors that influence students' decisions to cheat (or correlates of cheating), and (3) informing faculty and institutional policy for preventing cheating and for handling cheating incidents when they occur. As will be explained in the literature review, most literature pertaining to policy separates the construct of cheating into more specific behaviors on specific types of assessments, such as plagiarism on term papers and copying answers from other students on homework (Cizek, 1999; Whitley and Keith-Spiegel, 2002). However, most studies aimed at documenting prevalence and understanding correlates of cheating combine cheating behaviors on an assortment of assessments into a single measure of cheating, presenting an unfortunate obstacle to informing policy.

The purpose of our survey study was to understand the factors that explain the frequency of cheating by undergraduate engineering students on two types of assessments: exams and homework. To this end, we identified two dependent variables for use in this study: frequency of cheating on exams and frequency of cheating on homework. The blocks of independent variables used in the two analyses were demographics, pre-college cheating behavior, co-curricular participation, plus five blocks organized around the theory of planned behavior (Ajzen, 1991; Beck and Ajzen, 1991): moral obligation not to cheat; attitudes about cheating; evaluation of the costs and benefits of cheating; perceived social pressures to cheat or not to cheat; and perceived effectiveness of academic dishonesty policies. The sample selection controlled for the students' major. A secondary purpose of our study was to test Ajzen's theory of planned behavior (TPB) for predicting cheating behavior. 
Hierarchical multiple regression analyses were performed to determine how blocks of variables organized around the TPB work together to predict the two dependent variables.

\section{LITERATURE REVIEW}

In this section, we explain how we selected the TPB for organizing our independent variable in our respective models, and we describe the constructs in the theory and the construct we use to modify the basic theory. Next, we explain why we selected dependent variables based on the type of assessment by showing how the TPB, previous empirical work on cheating, and policy discussions pertaining to cheating all indicate that a decision to cheat is highly affected by the type of assessment. Then, we describe how we selected independent variables guided by the TPB and previous research on cheating. Finally, we share our rationale for selecting a sample composed entirely of engineering undergraduates.

\section{The Theory of Planned Behavior}

Two recent reviews of cheating among college students (Crown and Spiller, 1998; Whitley, 1998) each cite over 100 relevant studies published from 1970 to 1997. Only a few of the studies have used a theoretical framework to explain or predict cheating among college students. Theoretical frameworks used include models of deviance (used by Genereux and McLeod, 1995; Liska, 1978; Michaels and Miethe, 1989), deterrence theory (used by Buckley, Wiese, and Harvey, 1998; Cochran, Chamlin, Wood, and Sellers, 1999), cognitive consistency theory (used by Tang and Zuo, 1997), moral development models (used by LanzaKaduce and Klug, 1986; Whitley and Kost, 1999), rational choice theory (used by Buckley et al., 1998; Cochran et al., 1999; Tibbetts, 1997), anomie (used by Caruana, Ramaseshan, and Ewing, 2000), and the theory of planned behavior (used by Beck and Ajzen, 1991; Genereux and McLeod, 1995; Nonis and Swift, 2001; Whitley, 1998) or its earlier version, the theory of reasoned action (used by Pratt and McLaughlin, 1989). Because a number of researchers have demonstrated its applicability to academic cheating, we used the theory of planned behavior (Ajzen, 1991; Beck and Ajzen, 1991) as the theoretical framework for organizing our independent variables in our models. ${ }^{1}$

Ajzen's ${ }^{2}$ theory of planned behavior (TPB) postulates that human behavior is guided by rational decisions that are influenced by both the intention to perform the behavior and also a perception of control over 
the behavior (Ajzen, 1991). Intention is determined by three components: (1) attitude toward a behavior (Attitude), (2) perceived social pressures to engage in or not engage in the behavior (Subjective Norms), and (3) the perceived ease of performing the behavior (Perceived Behavioral Control). Note that beliefs are the antecedents of attitude, subjective norms, and perceived behavioral control. "Beliefs about the likely [positive and negative] consequences or other attributes of the behavior (behavioral beliefs)" (Ajzen, 2002, p. 665) produce the attitude toward the behavior. "Beliefs about the normative expectations of other people (normative beliefs)" (p. 665) lead to subjective norms, and "beliefs about the presence of factors that may further or hinder performance of the behavior (control beliefs)" (p. 665) result in perceived behavioral control. Further, perceived behavioral control is theorized to have a direct influence on both actual behavior and intention. The direct influence of perceived behavioral control on actual behavior allows for the study of behaviors that are not under the complete volitional control of the individual (Ajzen, 2002). Despite substantial support for the TPB as a means of predicting actual behavior (Armitage and Conner, 2001), research continues to examine variables that might enhance the predictive capabilities of the theory (Conner and Armitage, 1998). For example, Beck and Ajzen concede that "understanding the determinants of dishonest behaviors can be more problematic than understanding performance of socially acceptable behaviors" (1991, p. 300). They propose that factors in addition to those encompassed by the TPB, such as moral obligation, may be critical in understanding cheating and other dishonest behaviors. We include moral obligation as a modifying construct in the TPB for the purpose of organizing our independent variables.

\section{Rationale for the Selection of Dependent Variables}

The TPB implies that the precursors of intention to act will vary by situation, and consideration of each construct (attitude, subjective norms, and perceived behavioral control) for different assessment situations, such as exams and homework assignments, reveals that type of assessment should greatly affect each construct in the TPB resulting in different behaviors. This notion that the type of assessment will greatly affect behavior has been verified by multiple veins of literature as described below and is the basis for the selection of our dependent variables: frequency of exam cheating and frequency of homework cheating. 
Empirical Evidence that Prevalence of Cheating is Affected by the Type of Assessment

Several studies have reported on prevalence of cheating separately by type of assessment, finding differences in rates of engagement by assessment type (e.g., Baird, 1980; Bowers, 1964; Brown, 1996; Diekhoff et al., 1996; Hanson, 1990; Jensen, Arnett, Feldman, and Cauffman, 2002; McCabe, 1997; Michaels and Miethe, 1989; Stearns, 2001; Storch and Storch, 2002; data from McCabe's 1993 study reported in Whitley and Keith-Spiegel, 2002). Also, research has shown that two components of the TPB as applied to cheating differ by type of assessment: attitudes and perceived behavioral control. In the realm of attitude toward cheating behavior, two types of attitudes have been shown to differ by type of assessment, specifically, general attitudes (Jordan, 2001; Lipson and McGavern, 1993; Michaels and Miethe, 1989; Newstead et al., 1996; Nuss, 1984; Thorpe, Pittenger, and Reed, 1999) and evaluation of costs, benefits, and risks (Jensen et al., 2002; Lipson and McGavern, 1993; Michaels and Miethe, 1989). In the realm of perceived behavioral control, the ease or difficulty of performing the behavior has been shown to differ by type of assessment (Lipson and McGavern, 1993). Although several studies have addressed perceived social pressures (subjective norms in the TPB) (e.g., Jordan, 2001; Newstead et al., 1996; Whitley and Kost, 1999), none were found that report pressures by type of assessment.

Further evidence that prevalence of cheating is affected by the type of assessment is provided by 30-year trends. In a 1993 study, McCabe, et al. (2001) replicated a 1963 survey (Bower, 1964) of nine state universities. McCabe et al. found that while the number of students reporting that they had copied on a test or exam doubled from $26 \%$ to $52 \%$, the number who admitted to plagiarism declined slightly from $30 \%$ to $26 \%$. Over the same period, the number of students who said that they had done un-permitted collaboration on assignments more than quadrupled from $11 \%$ to $49 \%$. If the percentages had all risen or fallen in tandem, even if their values differed in magnitude, the data might have indicated that these different behaviors could and should be investigated as a single phenomenon. However, some fell as others rose and the changes occurred at different rates, which indicates that these behaviors are controlled by different mechanisms and should be studied separately.

\section{Treating “Cheating” as a Unitary Construct: A Flaw in Previous Research}

Thus, the TPB and empirical evidence both indicate that a decision to cheat is highly affected by the type of assessment. As we explain in this section, research on academic dishonesty, or cheating, has often suffered 
from the indiscriminant combination of widely varying behaviors that are fundamentally different. In this statement, we make two claims: (1) indiscriminant combination of behaviors is common in the literature, and (2) indiscriminant combination of behaviors is a problem because it treats fundamentally different behaviors as unitary. Woven into our support for these claims, we supply evidence for the indiscriminant combination of behaviors in two of the three main veins of cheating research: prevalence and correlates of cheating. We also discuss the third vein-policy.

A direct illustration of combining multiple behaviors into a single measure of cheating is Brown and Emmett's (2001) review of empirical studies of the prevalence of cheating among college students. They identified 22 studies, published over 33 years, which simply summed responses for separate behaviors ( 2 to 36 behaviors, mean $=11.5$ ) to create a single measure: "overall level of cheating" (p. 531). In the study that included 36 different behaviors (Stern and Havlicek, 1986), three of the specific behaviors are "copying from another student during a quiz or examination" (p. 133), "working in a group on a homework assignment that was assigned as individual work" (p. 134), and "'making up' sources for bibliographic citation" (p. 134). Respondents were asked about attitudes toward each behavior (i.e., whether or not the behavior is "academic misconduct" (p. 131)) and also about engagement in the behavior (i.e., whether or not the respondent had "done this at least once while in college" (p. 131)). Students classified the behaviors differently: for one of the 36 behaviors, $7 \%$ classified it as misconduct while for another behavior $96 \%$ classified it as misconduct. Despite the wide range in perceptions about the behaviors, all 36 were combined into a single measure of "frequency of misconduct" (p. 138).

A second illustration of combining multiple behaviors into a single measure of cheating is Whitley's (1998) meta-analysis of empirical studies of correlates of cheating among college students. For the 107 studies reviewed, Whitley created a single dependent measure of prevalence of "cheating" by combining 19 estimates of total cheating, 36 estimates of examination cheating, 12 estimates of homework cheating, and 9 estimates of plagiarism.

Such decisions to combine behaviors on all types of assessments into a single prevalence measure is typical of correlates research on cheating (e.g., Baird, 1980; Deikfhoff et al., 1996; Jordan, 2001; McCabe and Trevino, 1997; Tang and Zuo, 1997). Typically, researchers choose to create a single prevalence measure as the dependent variable by combining all cheating behaviors, regardless of the type of the assessment.

There is a notable exception to this trend of combining all behaviors into a single dependent variable. In a correlates study of cheating 
among college students, Pratt and McLaughlin (1989) used factor analysis on 26 behaviors relating to assessments such as examinations, homework, and writing term papers to create four separate dependent variables relating to "obtaining help in an examination situation" (p. 203), "obtaining help outside of a test situation" (p. 203), "obtaining unfair credit...in nontest situations" (p. 203-204), and directly substituting for an assessment, such as one person taking an examination for another or submitting a paper that someone else wrote. They found that "different path models fit different types of behaviors" (p. 214) for the 323 undergraduates in this multi-institutional study, substantiating our claim that prevalence of cheating is affected by type of assignment.

\section{Summary: Why Research Should Distinguish Between Types of Assessments}

The TPB and empirical evidence both indicate that a decision to cheat is highly affected by the type of assessment. Yet in two of the primary veins of cheating research, prevalence and correlates of cheating, cheating behaviors have almost always been combined indiscriminately. Recently concerns have been raised about this common practice by Crown and Spiller (1998), Whitley (1998), and Thorpe, et al. (1999) "treating all cheating behaviors as a whole may ignore important interactions among variables" (1999, p. 57).

In the third primary vein of cheating literature, policy pertaining to cheating, classifications by type of assessment dominate discussions in areas such as prevention and detection, policy, working definitions, and strategies for teachers who must deal with academic dishonesty (Cizek, 1999; Lipson and McGavern, 1993; Whitley and Keith-Spiegel, 2002). This dominance of categorization by type of assessment is echoed in two schemes for categorizing cheating behaviors. Pavela's (1978) scheme distinguishes between two broad classes of assessments - "cheating" and "plagiarism"- in addition to two types of behavior - "facilitation" and "fabrication". Whitley and Keith-Spiegel (2002) extend Pavela's categories by specifying type of assessment, such as cheating on examinations and cheating on assignments. Collectively, studies in all three veins of cheating research demonstrate the need to use distinct dependent variables for each type of assessment in any research on cheating behavior.

Thus, to evaluate whether the prevalence of cheating is affected by type of assessment, we separated our analyses by type of assessment. Of the many available types of assessments, we chose two dependent variables: frequency of cheating on exams (an index of nine exam cheating behaviors from our survey) and frequency of cheating on homework (an index of four homework cheating behaviors) (Table 1). We selected 
PASSOW, MAYHEW, FINELLI, HARDING, AND CARPENTER

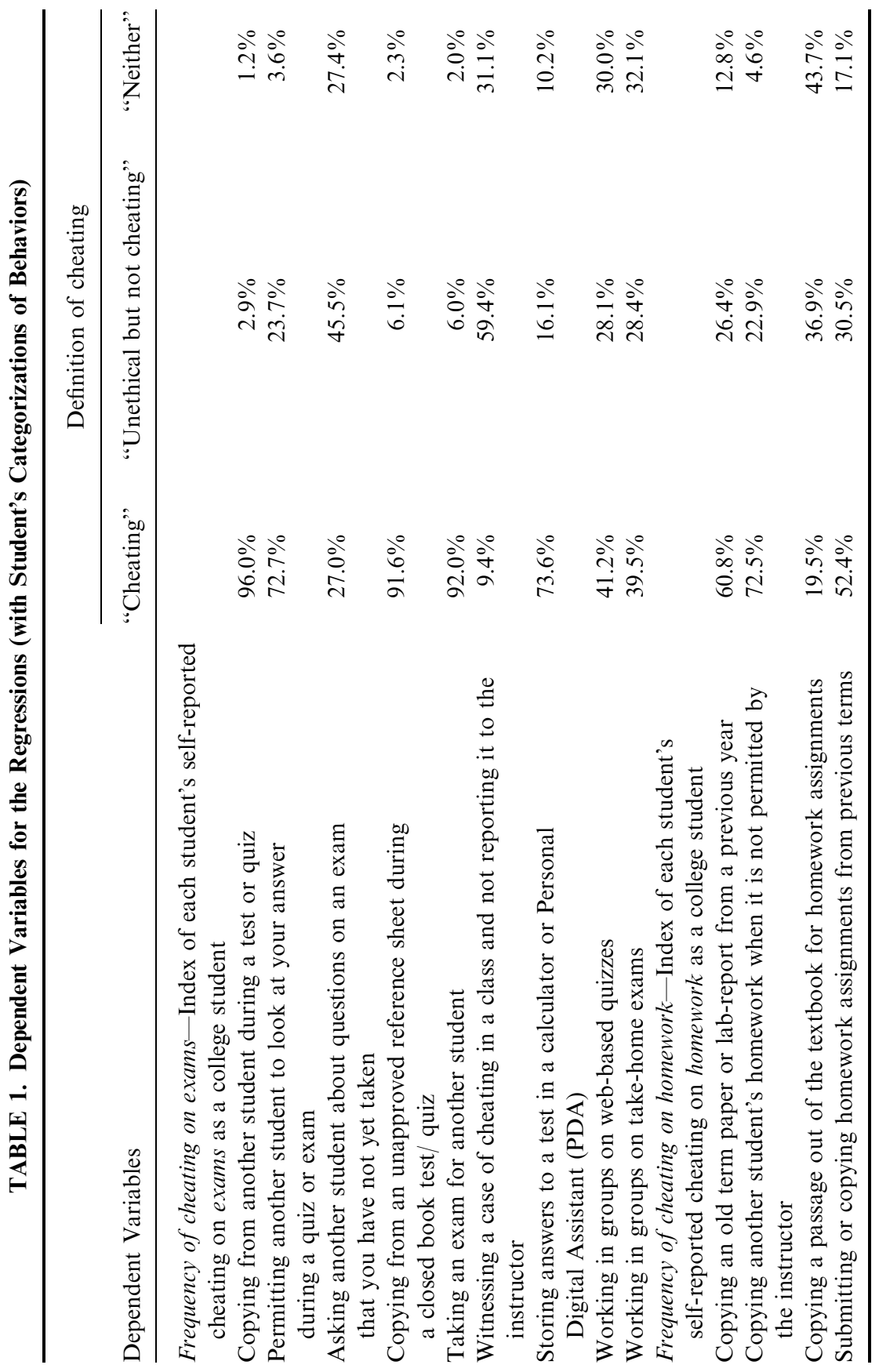


exams and homework because they are the backbone of assessment in many mathematics, science, and engineering courses. Surprisingly, homework cheating behaviors have almost never been distinctly included in cheating surveys. We selected only behaviors that at least $50 \%$ of the respondents defined as either "cheating" or "unethical but not cheating" because previous research has shown that cheating is difficult to define (e.g., Kibler, Nuss, Paterson, and Pavela, 1988; Ratner, 1996) and that students often do not define a behavior as cheating even when faculty do (e.g., Stern and Havlicek, 1986; Whitley and Keith-Spiegel, 2002).

\section{Rationale for the Selection of Independent Variables}

Our 139-item survey was designed based on a review of literature on academic dishonesty (Carpenter, Harding, Montgomery, and Steneck, 2002; Harding, Carpenter, Montgomery, and Steneck, 2001). For our analysis, we selected 37 items (Table 2) for our independent variables. Thirty-three individual items refer to cheating in general with no possible reference to any particular type of assessment. Another four items used as independent variables are a matched set: two refer unambiguously to exam cheating and two have parallel wording but refer to homework. Only the two exam items were used as independent variables in the exam cheating model, and only the two homework items were used as independent variables in the homework cheating model. The selected independent variables were organized into eight blocks according to demographics, pre-college cheating behavior, co-curricular participation, and five blocks organized around the TPB. As noted below, variables were checked for effect size (small, medium, or large) and statistical significance in Whitley's (1998) meta-analysis, which was also based on the TPB. All correlations listed below are from Whitley (1998) unless otherwise noted.

The demographics block is composed of age (negative correlation, medium effect), gender (males more likely, small effect), socioeconomic status (parental education - positive correlation, small effect in a single study), year in college (no correlation), and grade point average (negative correlation, small effect). Our pre-college cheating behavior block is a single variable, frequency of high school cheating (related to Whitley's "have cheated in the past" (p. 257), positive correlation, large effect). Variables in the co-curricular participation block are membership in a fraternity or sorority (positive correlation, small effect) and involvement in clubs, teams, professional societies, or community service organizations (positive correlation, small effect).

There are five blocks of independent variables organized around our theoretical framework: the TPB. Our purpose was to organize our study 
PASSOW, MAYHEW, FINELLI, HARDING, AND CARPENTER

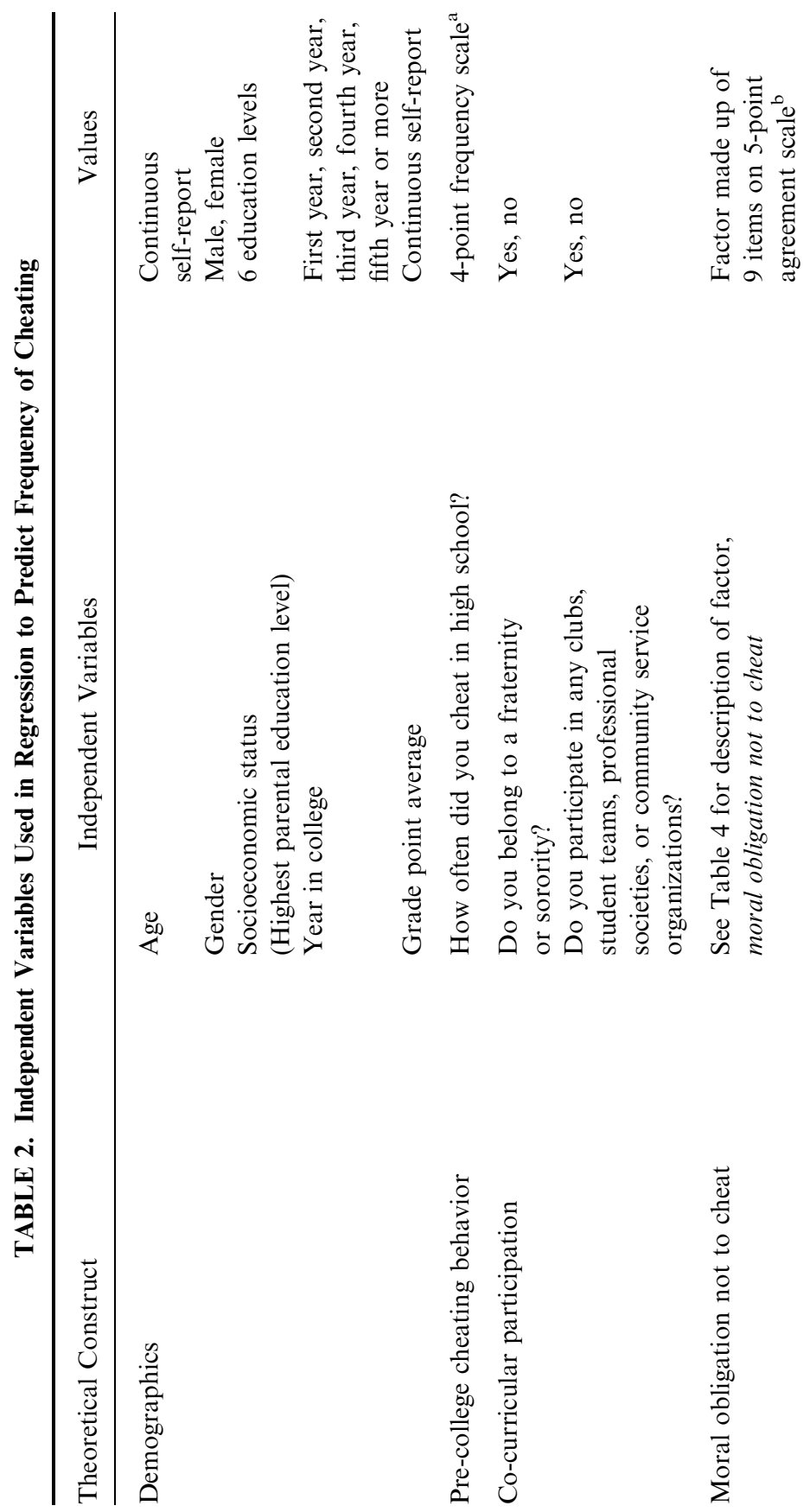


CORRELATES OF CHEATING BY TYPE OF ASSESSMENT


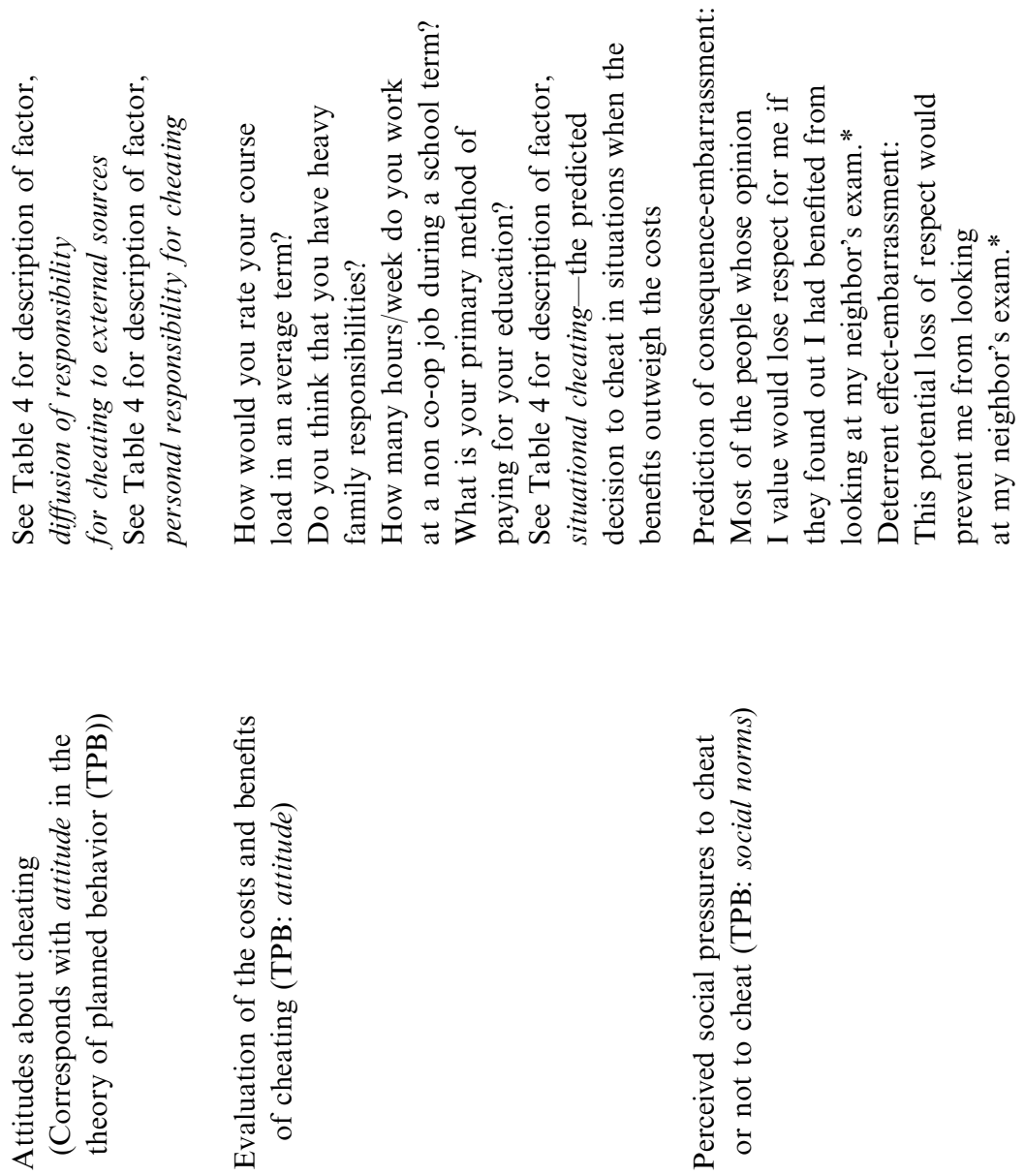
PASSOW, MAYHEW, FINELLI, HARDING, AND CARPENTER

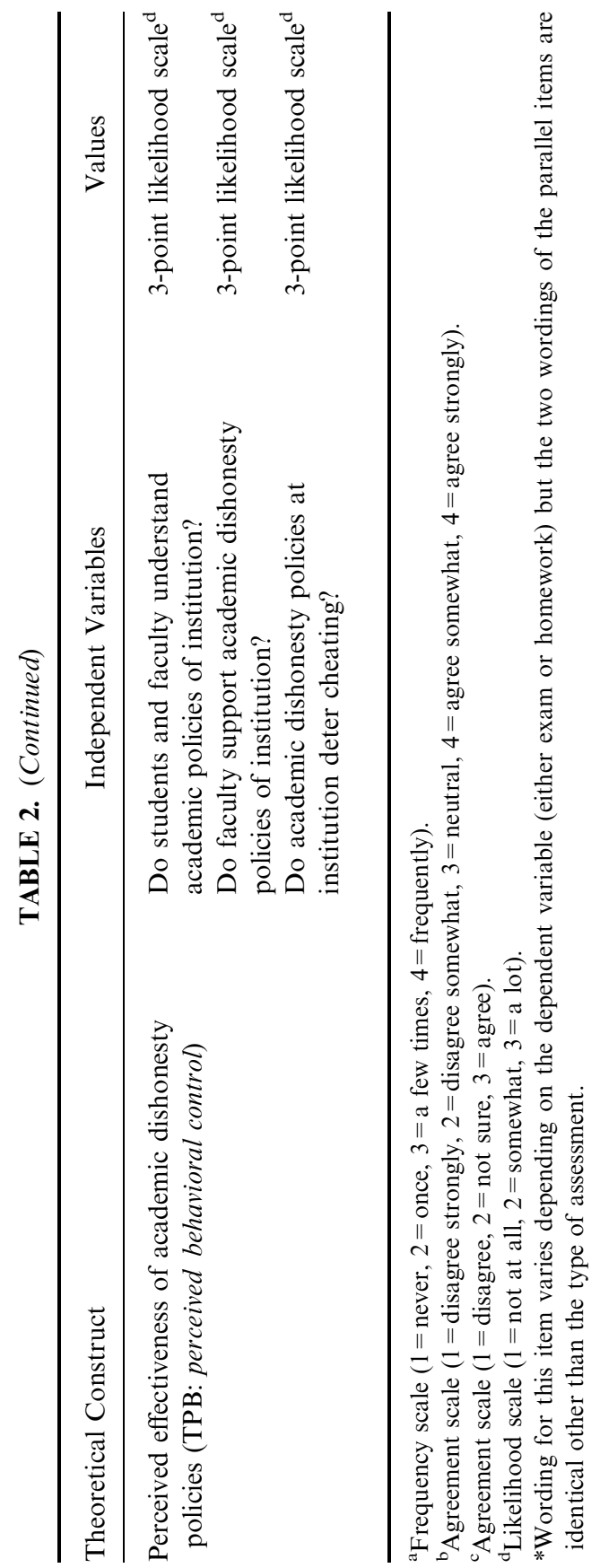


around a theoretical framework that previous research has shown is useful in describing cheating behavior. We separated the block that we named moral obligation not to cheat (negative correlation, medium effect) from attitudes about cheating per Beck and Ajzen's (1991) adjustment to the TPB when applied to dishonest behaviors. This block was a single factor composed of nine items.

We split the TPB construct of attitude into two blocks. One block, general attitudes about cheating, is composed of two factors on attitudes about responsibility for cheating. Although Whitley's meta-analysis includes a number of attitudes about cheating, some of which have large effects, our survey items did not match the essence of his constructs, and so cannot be compared directly. In another block, evaluation of the costs and benefits of cheating, we include pressures that students typically experience: course load (positive correlation, medium effect); family responsibilities (this apparently pertinent pressure was not included in Whitley's meta-analysis); employment responsibilities (Whitley included an odd dichotomous variable from fewer than five effect sizes. His finding, a small effect, was that students employed less than full time were more likely to cheat.); and means for financing education (students "supported by their parents" (p. 257) were more likely to cheat than an undefined reference case, small effect). Also included in this block is a factor of four items that propose a situation in which the respondent would be under pressure and ask for a prediction of a decision to cheat or not. These items embody several effects in Whitley's meta-analysis (p. 257--258): "feel pressure to get high grades" (positive correlation, medium effect), are "faced with important outcomes" (positive correlation, medium effect), "perceive a higher benefit-to-risk ratio" (positive correlation, medium effect), and "perceiving higher competition for grades" (positive correlation, medium effect).

The block corresponding to the TPB's subjective norms is perceived social pressures to cheat or not to cheat. In this block, we include predicted feelings of embarrassment after a decision to cheat and the deterrent effect of those predicted feelings (oppositely related to Whitley's "perceive that norms allow cheating" (p. 257) which had a positive correlation, large effect).

Our survey's only reference to the TPB construct of perceived behavioral control was three items referring to perceived effectiveness of academic dishonesty policies. In this block, we include three items about student and faculty understanding of academic dishonesty policies, faculty support for those policies, and the deterrent effect of those policies. Related items in Whitley's meta-analysis are: subjection to honor codes (negative correlation, medium effect) and "expect less punishment if caught" (p. 258) (positive correlation, small effect). 


\section{Rationale for the Selection of the Sample}

Our sample, comprised entirely of engineering undergraduates at eleven institutions, is appropriate for our analysis for three reasons. First, because students in different majors engage in cheating at different rates, using a sample of students exclusively from one area of study controls for students' major. Second, engineering students self-report higher frequencies of cheating than all other majors except for business majors, yet, other than our own research (Carpenter et al., 2002; Carpenter, Harding, Montgomery, Steneck, and Dey, 2002; Finelli, Harding, Carpenter, and Passow, 2003; Harding, 2000, 2001; Harding, et al., 2001; Harding, Carpenter, Montgomery, and Steneck, 2002; Harding et al., 2003, 2004), we know of only nine studies of cheating have specifically distinguished engineering students from students in other majors (Bowers, 1964; Brown, 1994, 1996; Harp and Taietz, 1966; McCabe, 1997; Newstead et al., 1996; Shaughnessy, 1988; Singhal, 1982; Sisson and Todd-Mancillas, 1984). Of these, only Bowers (1964) and McCabe (1997) conducted multi-institutional studies. Third, the importance of studying cheating among engineering undergraduates $(100 \%$ of our sample) is heightened by nationwide emphases among engineering faculty on assessing student learning outcomes and explicitly teaching professional ethics. Both of these emphases were codified in changes to the nationwide accreditation requirements for engineering programs (Moore, 1996) and are still in effect (Engineering Accreditation Commission, 2004).

\section{Rationale for Using Blocked-Hierarchical Analysis}

We had two goals for our analysis: (1) to allow comparison of the patterns in the relationships between the independent variables and the two dependent variables and (2) to test Ajzen's TPB for predicting cheating behavior. By entering variables into the models in hierarchical blocks, we achieved both goals.

\section{RESEARCH QUESTIONS}

Altogether, the TPB includes the three elemental constructs of attitude, subjective norms, and perceived behavioral control. For dishonest behaviors such as cheating, moral obligation is an additional construct in the theory. We used the TPB, which has proven effective in describing cheating behavior, as a theoretical framework for organizing our 
independent variables in our models. Based on the items in our survey, we represented TPB constructs with five blocks of variables: moral obligation not to cheat; attitudes toward cheating; evaluation of the costs and benefits of cheating; perceived social pressures to cheat or not to cheat; and perceived effectiveness of academic dishonesty policies. Our research addressed three questions:

1. Which of the constructs represented by these five blocks of variables predict the frequency of cheating on exams among engineering students?

2. Which of the constructs represented by these five blocks of variables predict the frequency of cheating on homework among engineering students?

3. Among engineering students, what are the differences in the predictive power of these constructs for cheating on two different types of assessments: exams and homework?

\section{METHODS}

\section{Data Collection}

Survey Instrument, Distribution, and Collection

Our study is based on data collected during the 2001 calendar year using a direct-question survey. After a review of studies of college cheating (Carpenter et al., 2002), the survey was designed to identify perceptions and attitudes about cheating on the types of assessments typical in engineering curricula, including exams, homework, and calculator usage. Questions were strongly influenced by Cochran, et al. (1999), McCabe and Trevino (1993), and McCabe, Trevino, and Butterfield (1999). The survey was designed to incorporate published empirical findings and was not based on theory. The items we selected for this study fitted the TPB.

The seven-page survey contains 139 questions, subdivided into seven parts. Part 1 addresses students' definitions of cheating and the frequency with which they have engaged in twenty distinct cheating behaviors. Parts 2 through 5 investigate attitudes, beliefs, and situational factors that might affect a student's decision to cheat or not. Part 6 addresses deterrents to cheating and students' perceptions of their effectiveness, and Part 7 covers student demographics. We reduced the possibility of underreporting due to desirability by posing questions in a manner that assumed the behavior had occurred (Sudman and Bradburn, 1982). 


\section{Sample: Institutions}

The survey was completed by 695 students (643 undergraduates) in engineering and pre-engineering courses at eleven institutions in the United States and abroad, including large public universities, small private universities, and community colleges (Table 3). Student participation in the study was voluntary and unmonitored, and the students and institutions were informed that results would remain anonymous to protect each participant. Institutions were selected based on the willingness of a faculty member to distribute the surveys in a course. Thus, our sample of convenience is not necessarily representative of the engineering students on any single campus or of the types of institutions involved.

\section{Response Rate}

Because of the informal method of selecting volunteer faculty to distribute surveys for this study, records that would enable the calculation of response rates were not kept. However, in each class in which the survey was distributed, nearly all students completed the survey-yielding an estimated response rate above $90 \%$. Possibly because of the length of the survey, several students did not respond to all questions and the response rate declined near the end of the survey. For statistical analysis, list-wise deletion was used to ensure that our study included only respondents who answered all the items we selected for our analysis.

TABLE 3. Demographic Information for Institutions in the Data Set

\begin{tabular}{lccc}
\hline Carnegie Classification (in 2000) & $\begin{array}{c}\text { Number of } \\
\text { respondents }\end{array}$ & $\begin{array}{c}\text { Percent of } \\
\text { respondents }\end{array}$ & $\begin{array}{c}\text { Number of } \\
\text { institutions }\end{array}$ \\
\hline Doctoral/Research Universities_Extensive & 205 & 29.5 & 3 \\
Doctoral/Research Universities_-Intensive & 42 & 6.0 & 1 \\
Master's Colleges and Universities I & 233 & 33.5 & 3 \\
Associate's Colleges & 42 & 6.0 & 2 \\
Specialized Institutions: Schools of & 138 & 19.9 & 1 \\
$\quad$ Engineering and Technology & 30 & 4.3 & 1 \\
International & 5 & 0.7 & - \\
Institutional Affiliation Unknown & & & \\
$\quad$ for Respondent & 695 & 100.0 & 11 \\
Totals & &
\end{tabular}




\section{Sample: Respondents}

The mean age of students in the analytical sample $(n=643)$ was 21.6 years with a range of 17 to 48 years of age. A total of $81.2 \%$ of respondents were male and $18.8 \%$ female, which is close to U.S. national figures. (In the most recent data published by the National Science Board of the National Science Foundation (2004), 20.5\% of all engineering bachelor's degrees granted in 2000 were granted to females). Information on students' ethnicity and race was not collected for reasons of protecting student identities within small sample subsets.

There was a wide range of socioeconomic status with parents' household incomes ranging from less than $\$ 20,000$ ( $7.3 \%$ of respondents) to more than $\$ 200,000(6.6 \%)$ annually. Only $31.3 \%$ of respondents indicated their parents were the primary method of paying for college, with $41.3 \%$ paying their own way and $27.5 \%$ on scholarship. Most respondents $(78.8 \%)$ were raised in the United States, including $59.0 \%$ who were from the Midwest.

There is a variety of class level in this sample: $22.9 \%$ of respondents reported they were in their first year, $13.7 \%$ were in their second year, $24.1 \%$ were in their third year, $21.3 \%$ were in their fourth year, and $18.0 \%$ were in their fifth year (or more) of their undergraduate engineering career. In addition, the discipline of engineering with which the participants were affiliated represents a wide variety-surveys were administered in first year engineering or pre-engineering programs and to students in electrical, civil, chemical, and mechanical engineering courses.

The mean grade point average of students in the sample was approximately a $3.2 \pm 0.5$ on a 4.0 scale, and a majority of students $(59.7 \%)$ indicated they typically carried a heavy course load. Some of the respondents $(12.9 \%)$ had at least one dependent, with $3.6 \%$ having three or more dependents. For this sample, $18.9 \%$ of the students were members of a fraternity or sorority. Further, $64.1 \%$ participated in some form of student team, professional society, or community service organization. Finally, $29.0 \%$ of respondents reported that they never cheated in high school, while $60.6 \%$ admitted to cheating in high school more than once.

\section{Variables}

We investigated two dependent variables for this study. Both variables are summative indices of items from a 20-part question: one reflecting self-reported frequency of cheating on exams and the other reflecting self-reported frequency of cheating on homework. The question read: "if you have ever engaged in any of these actions as a college 
student please indicate how many times you have engaged in [it]". This question was followed by a list of 20 specific "cheating" behaviors, including the thirteen behaviors selected for this study (the behavior items are listed in Table 1). The time period for these questions was defined by the question, which asked how many times the respondent engaged in the action "as a college student". The frequency of cheating on exams dependent variable was constructed by summing nine items. Similarly, the frequency of cheating on homework variable was created by summing four items. Dependent variables were standardized for ease of interpretation across models and both are normally distributed.

Independent variables were organized into eight blocks around a theoretical framework (Ajzen's TPB): student demographics (i.e., age, gender, socioeconomic status, year in college, and grade point average); pre-college cheating behavior; co-curricular participation (i.e., fraternity and sorority membership and club participation); moral obligation not to cheat (a single factor composed of nine items); attitudes about cheating (a two-item factor and a three-item factor); evaluation of the costs and benefits of cheating (one four-item factor and four separate items); perceived social pressures to cheat or not cheat (two items); and perceived effectiveness of academic dishonesty policies (three items). Table 2 presents an overview of independent variables including a description of the scale for each item.

\section{Analysis}

Descriptive and exploratory analyses were performed on the 13 individual items which, when summed and standardized, comprise the two dependent variables for this study, frequency of cheating on exams and frequency of cheating on homework. These analyses identify which behaviors the respondents defined as cheating, as unethical but not cheating, or as neither unethical nor cheating (Table 1). In order to reduce the number of independent variables used in the regression model, exploratory factor analyses were conducted using principle axis factoring and orthogonal rotation methods. Factor loadings that contained a score of at least .69 or higher were used in the development of subsequent summated scales. Internal validity for each of these scales was high, with Cronbach's alpha reliabilities ranging from .69 to .95 . Table 4 contains a complete description of the four factors used in the final model for this study.

Hierarchical multiple regression analyses were performed to determine how the eight blocks of independent variables work together to predict the two dependent variables used for this study. Regression diagnostics 
TABLE 4. Variable Names, Loadings and Reliability of Factors Created for this Study

Scale and Individual Item Measures

Loading Alpha

Moral obligation not to cheat .95

Indicate the extent to which you agree. $1=$ Strongly disagree, $2=$ Disagree, $3=$ Neutral, $4=$ Agree, $5=$ Strongly agree

It is wrong to cheat even if the course material was too hard

$\begin{array}{ll}\text { It is wrong to cheat even if other students' scores are not affected } & .89\end{array}$

It is wrong to cheat even if I am in danger of failing the class $\quad .86$

It is wrong to cheat even if the instructor assigned too much $\quad .86$ material

It is wrong to cheat even if the course material seemed useless $\quad .86$

It is wrong for me to cheat even if the instructor does not grade $\quad .86$ fairly

It is wrong to cheat even if the instructor has done an inadequate job of teaching the course

It is wrong to cheat even if the instructor didn't seem to care if I learned the material

It is wrong to cheat no matter what the circumstances

Situational cheating-Predicted decision to cheat in situations

when the benefits outweigh the costs

Indicate the extent to which you agree. $1=$ Strongly disagree, $2=$ Disagree, $3=$ Neutral, $4=$ Agree, $5=$ Strongly agree

$\begin{array}{ll}\text { I would cheat if doing so helped me retain financial assistance } & .88\end{array}$

I would cheat to avoid letting my family down if I failed $\quad .87$

I would cheat to avoid getting a poor or failing grade in class $\quad .85$

$\begin{array}{ll}\text { I would cheat in a class if it seemed that everyone else was cheating } & .82\end{array}$

Diffusion of responsibility for cheating to external sources

Indicate the extent to which you agree. $1=$ Strongly disagree, $2=$ Disagree, $3=$ Neutral, $4=$ Agree, $5=$ Strongly agree

It is the institution's responsibility to prevent cheating

It is the instructor's responsibility to prevent cheating

Personal responsibility for cheating

Indicate the extent to which you agree. $1=$ Strongly disagree, $2=$ Disagree, $3=$ Neutral, $4=$ Agree, $5=$ Strongly agree

If I saw another student cheating, I would report

the student to the instructor

If I saw another student cheating, I would confront the student

It is my responsibility to prevent cheating 
suggested that the assumptions of normality, linearity, and homogeneity were met. Two variables were recoded for use in the regression model: year in college (dummy coded with first-year serving as the reference group) and means for financing education (dummy coded with "paying own way" serving as the reference group). In addition, due to the different bases for the grade point averages at each institution, we transformed the grade point average variable for each student using the mean and standard deviation for that student's institution and then combined these transformations into a single variable for grade point average.

A structured, blocking approach was used to add variables to the respective models. This procedure yielded an eight-construct solution for each model. Tables 5 and 6 contain a complete description of the standardized regression coefficients for each variable used in each model. In addition, we present the parameter estimates for the final models for both dependent variables in Table 7 for ease of comparison.

\section{RESULTS}

\section{Model 1: Frequency of Cheating on Exams}

The final model significantly predicts $36 \%$ of the variance in the dependent variable frequency of cheating on exams, $F(25,585)=14.35$, $p<.0001$. Five of the eight blocks of variables (i.e., pre-college cheating behavior, co-curricular participation, moral obligation not to cheat, attitudes about cheating, and evaluation of the costs and benefits of cheating) contributed significantly to this dependent variable.

\section{Demographics}

The first block of variables, demographics, explains $2 \%$ of the variance in the dependent variable, frequency of cheating on exams. The only variable that reaches statistical significance is year in college: students in their "fifth year (or more)" are more likely to report cheating on exams than first-year students $(\beta=.14, p<.01)$.

\section{Pre-college Cheating Behavior}

The second block, which contains a single-item indicator that measures frequency of cheating in high school, contributes a significant $10 \%$ of the variance in the dependent variable beyond the variance explained by demographics. Students who report cheating more often in high 
school also are more likely to report cheating on exams in college $(\beta=.32, p<.001)$.

Effects for year in college remained significant after adding the second block of variables. In addition to significant differences between students in their fifth year (or more) and first-year students, fourth-year students are also more likely to report cheating on exams than first-year students $(\beta=.10, p<.05)$ after adding pre-college cheating behavior to the model.

\section{Co-curricular Participation}

Controlling for demographics and pre-college cheating behavior, the block of variables that included measures of the students' co-curricular participation significantly explained an additional $2 \%$ of the variance in the dependent variable. Students who participated in fraternities and sororities were more likely to report cheating on exams than unaffiliated students $(\beta=.11, p<.01)$.

Effects for year in college (comparing students in their "fifth year (or more)" to first-year students and fourth-year students to first-year students) and pre-college cheating behavior remained statistically significant.

\section{Moral Obligation Not to Cheat}

Students' moral obligation not to cheat significantly explained an additional $16 \%$ of the variance in the dependent variable beyond the variance explained by demographics, pre-college cheating behavior, and co-curricular participation. On average, students who believed that cheating was wrong were significantly less likely to report cheating on exams $(\beta=-.42, p<.001)$. After adding this block, year in college differences, pre-college cheating behavior, and membership in a fraternity or sorority remained statistically significant.

\section{Attitudes About Cheating}

Controlling for demographics, pre-college cheating behavior, co-curricular participation, and moral obligation not to cheat, variables comprising the "attitudes about cheating" block significantly explained an additional $2 \%$ of the variance in the dependent variable. Specifically, students who felt personally responsible for preventing cheating were significantly less likely to cheat on exams $(\beta=-.13, p<.001)$. After adding this block, year in college differences, pre-college cheating behavior, 
PASSOW, MAYHEW, FINELLI, HARDING, AND CARPENTER

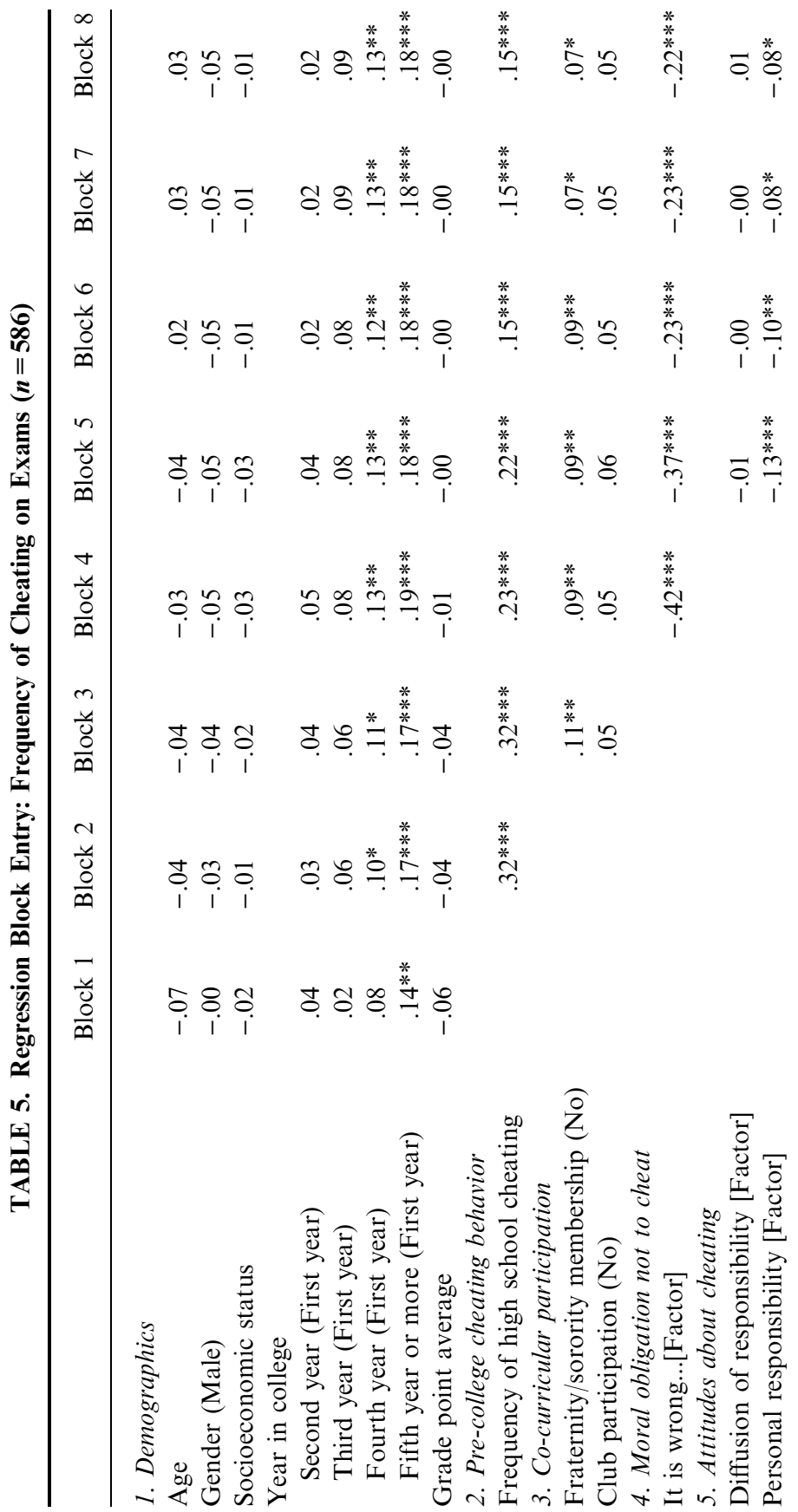


CORRELATES OF CHEATING BY TYPE OF ASSESSMENT

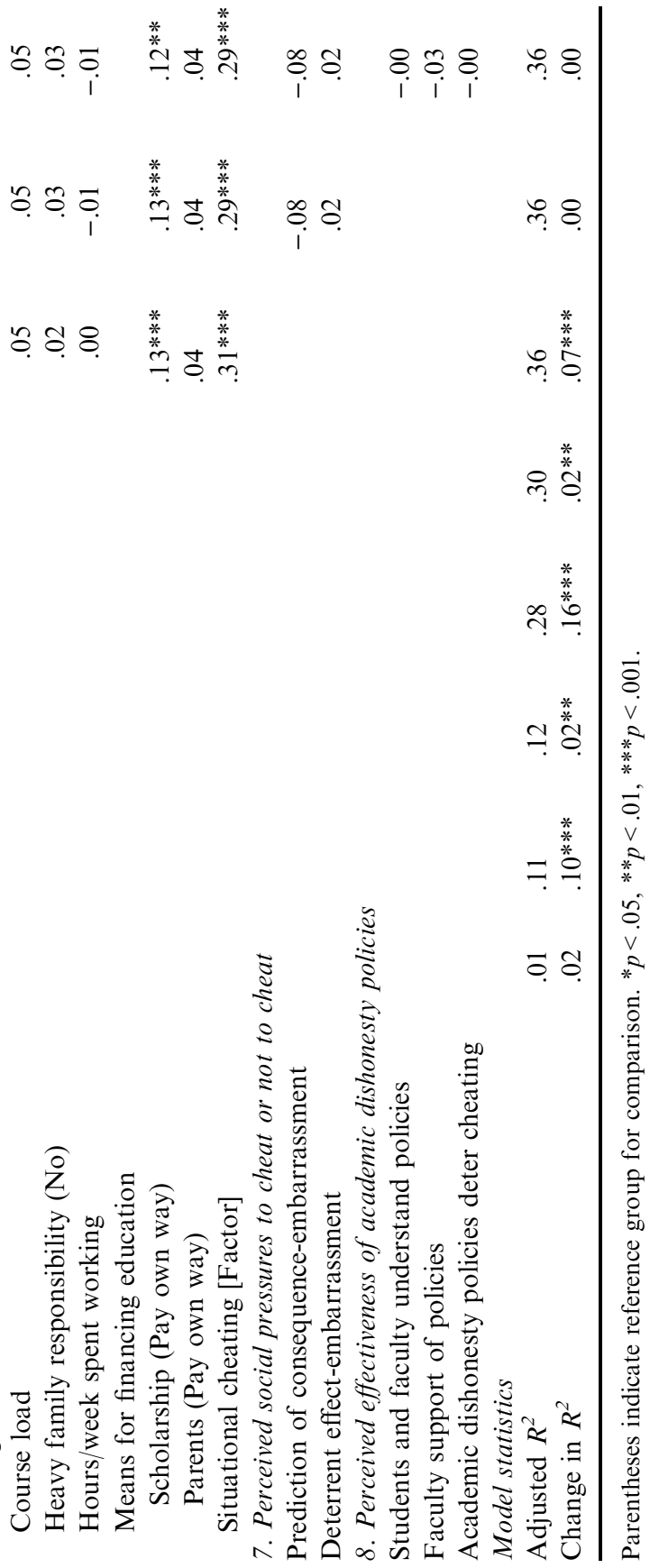


PASSOW, MAYHEW, FINELLI, HARDING, AND CARPENTER

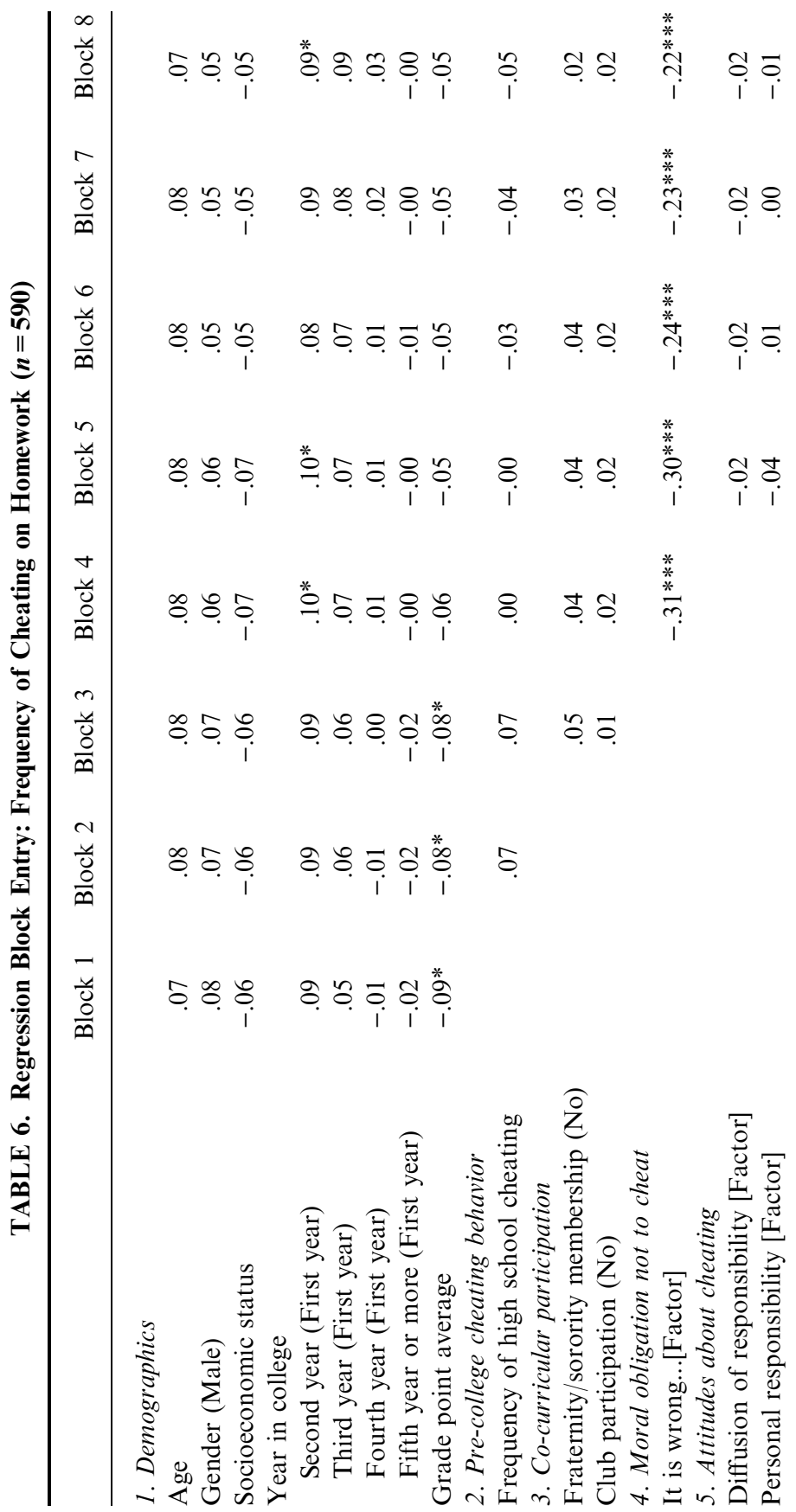


CORRELATES OF CHEATING BY TYPE OF ASSESSMENT

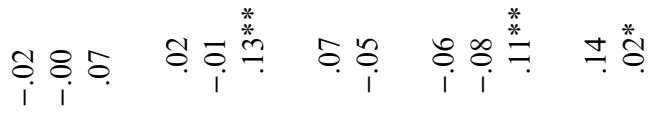

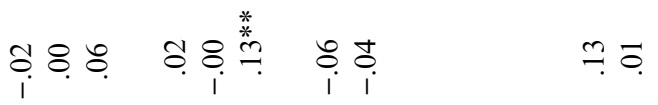

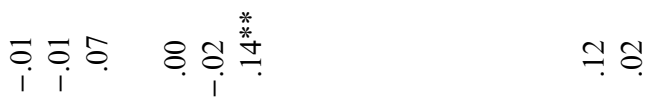

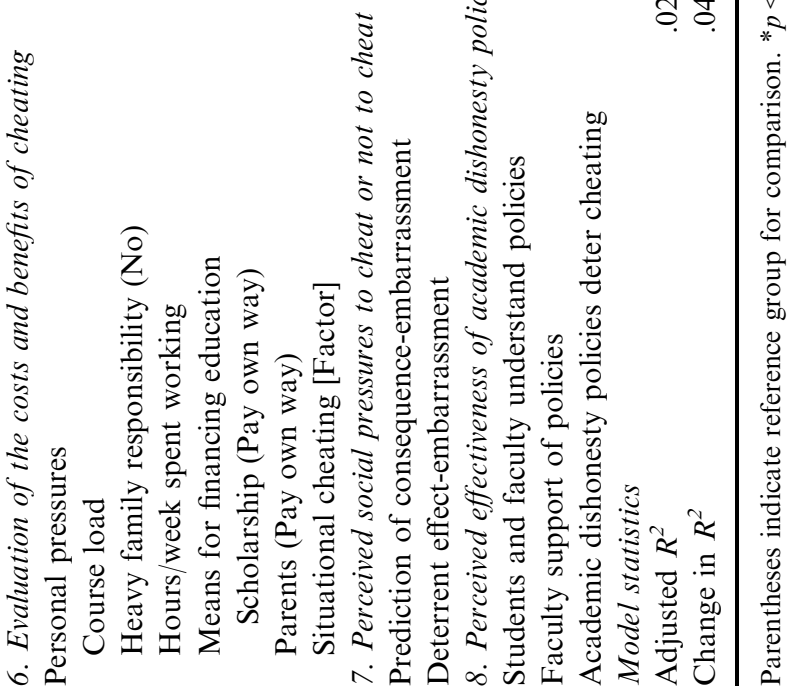


membership in a fraternity or sorority, and moral obligation not to cheat remained statistically significant.

\section{Evaluation of the Costs and Benefits of Cheating}

Controlling for demographics, pre-college cheating behavior, co-curricular participation, moral obligation not to cheat, and attitudes about cheating, items comprising the "evaluation of the costs and benefits of cheating" block significantly explained an additional $7 \%$ of the variance in the dependent variable. Specifically, students on scholarship were more likely to report cheating on exams than students who paid for college on their own $(\beta=.13, p<.001)$. Similarly, student who agreed that "I would cheat...[to alleviate a stressful situation]" such as to maintain financial assistance, to avoid failing, to avoid letting their family down, and to go along with the crowd were significantly more likely to cheat on exams $(\beta=.31, p<.001)$.

All of the aforementioned variables making up year in college, precollege cheating behavior, moral obligation not to cheat, and attitudes about cheating remained statistically significant.

\section{Perceived Social Pressures and Perceived Effectiveness of Academic Dishonesty Policies}

Variables making up the remaining blocks, "perceived social pressures to cheat or not to cheat" and "perceived effectiveness of academic dishonesty policies" explained $0 \%$ of additional variance in the dependent variable beyond the variance explained by the first six blocks of variables in the model. Consistent with our other findings, effects of the aforementioned variables making up year in college, pre-college cheating behavior, moral obligation not to cheat, attitudes about cheating, and evaluation of the costs and benefits of cheating remained statistically significant.

\section{Model 2: Frequency of Cheating on Homework}

The final model significantly predicts $14 \%$ of the variance in the dependent variable, frequency of cheating on homework, $F(25$, $589)=4.80, p<.0001$. Three of the eight blocks of variables (i.e., demographics, moral obligation not to cheat, and perceived effectiveness of academic dishonesty policies) contributed significantly to explaining the variance in this dependent variable. 


\section{Demographics}

The first block of variables measuring demographics explains a significant $4 \%$ of the variance in the dependent variable, frequency of cheating on homework. Students with higher grade point averages are less likely to report cheating on homework $(\beta=-.09, p<.05)$.

\section{Pre-college Cheating Behavior}

The second block containing a single-item indicator that measures frequency of cheating in high school contributes only $1 \%$ of the variance in the dependent variable beyond the variance explained by demographics. Effects for self-reported grade point average remained significant after adding the second block of variables.

\section{Co-curricular Participation}

Controlling for demographics and pre-college cheating behavior, the block of variables that included measures of co-curricular participation did not explain any additional variance in the dependent variable. Effects for grade point average stayed the same.

\section{Moral Obligation Not to Cheat}

Students' moral obligation not to cheat significantly explained an additional $9 \%$ of the variance in the dependent variable beyond the variance explained by demographics, pre-college cheating behavior, and co-curricular participation. On average, students who reported that cheating was "wrong" were significantly less likely to report cheating on homework $(\beta=-.31, p<.001)$. Effects for year in college (second-year students compared to first-year students) became statistically significant after adding this block $(\beta=.10, p<.05)$, meaning that when compared with first-year students, second-year students are significantly more likely to report cheating on homework. However, grade point average was driven out of statistical significance.

\section{Attitudes About Cheating}

Controlling for demographics, pre-college cheating behavior, co-curricular participation, and moral obligation not to cheat, variables comprising attitudes about cheating significantly explained an additional $0 \%$ of the variance in the dependent variable. Effects for both year in college (second-year students compared to first-year students) and moral 
obligation not to cheat remained statistically significant predictors of the dependent variable, even after adding this new block of variables.

\section{Evaluation of the Costs and Benefits of Cheating}

Controlling for demographics, pre-college cheating behavior, co-curricular participation, moral obligation not to cheat, and attitudes about cheating, items comprising the "evaluation of the costs and benefits of cheating" block explained an additional $2 \%$ of the variance in the dependent variable. Specifically, students who agreed that "I would cheat...[to alleviate a stressful situation]" (i.e., in situations when the respondent deemed the benefits of cheating outweighed the costs) were more likely to report cheating on homework $(\beta=.14, p<.01)$.

After adding this additional set of variables into the model, the effects of students' moral obligation not to cheat remained statistically significant. However, the difference in cheating on homework between secondyear students and first-year students fell out of significance.

\section{Perceived Social Pressures to Cheat or Not to Cheat}

Variables making up the block "perceived social pressures to cheat or not to cheat" explained an additional $1 \%$ of the variance in the dependent variable beyond the variance explained by the first six blocks of variables in the model. Consistent with our other findings, effects of students' moral obligation not to cheat and evaluation of the costs and benefits of cheating remained statistically significant.

\section{Perceived Effectiveness of Academic Dishonesty Policies}

Controlling for all other variables in the model, the remaining block, "perceived effectiveness of academic integrity policies," significantly explained $2 \%$ of additional variance in homework cheating beyond the variance explained by the first seven blocks of variables in the model. Students who believed that the academic policies at the institution deterred cheating were more likely to report cheating on homework $(\beta=.11, p<.01)$.

After adding this block of variables to the model, one effect of year in college became statistically significant: second-year students are more likely to report cheating than first-year students. Consistent with our other findings, students' moral obligation not to cheat and the aforementioned significant variable from the student's evaluation of the costs and benefits of cheating remained statistically significant. 


\section{DISCUSSION}

\section{Correlates of Cheating Vary by Type of Assessment}

The differences in the regression models for exam cheating and homework cheating (Table 7) clearly demonstrate that correlates of cheating vary by type of assessment. Evidence that correlates of cheating vary by type of assessment is the statistically significant differences in the six independent variables that predict either frequency of cheating behavior for exams and for homework but do not predict both (i.e., year in college, pre-college cheating behavior, fraternity/sorority membership, personal responsibility for cheating, means for financing college, and academic dishonesty policies deter cheating). Further evidence is the difference in the percentage of the variance explained by the parallel models (36\% for exam cheating and $14 \%$ for homework cheating). This dramatic difference indicates that the factors selected for this model predict exam cheating well but that other factors not included in the model must also contribute to predictions of homework cheating; in other words, the difference in how well the model fits each variable demonstrates that frequency of exam cheating is a different construct than frequency of homework cheating.

Cheating patterns vary by year in college. First-year students reported the least frequent cheating on both exams and homework. Although 4th year and 5th year undergraduates cheat significantly more than first year students on exams, second year undergraduates cheat significantly more than first year students on homework. Perhaps cheaters are dishonest on a type of assessment with a lower risk of detection (such as homework) in their early years at college and progress to cheating on higher-benefit, but higher-risk assessments (such as exams) in their later years at college as they develop skill at cheating without detection. This is consistent with the TPB (Ajzen, 1991) because in typical engineering courses, exam scores make up the majority of the course grade while homework is worth a small percentage of the course grade. However, the wording of the survey item complicates this explanation because if respondents carefully interpreted our survey question ("if you have ever engaged in any of these actions as a college student please indicate how many times you have engaged in [it]") as a cumulative total of all their cheating during college, a student who cheats at a steady annual rate would report an increased number of engagements with each passing year. Alternately, if many respondents misinterpreted this question as pertaining to a shorter period, such as an academic year or a semester, 
TABLE 7. Comparison of Unstandardized B-Weights between Dependent Variable in the Two Models (for Block 8), Exam and Homework

\begin{tabular}{|c|c|c|}
\hline & Exam & Homework \\
\hline \multicolumn{3}{|l|}{ 1. Demographics } \\
\hline Age & .01 & .02 \\
\hline Gender (Male) & -.11 & .12 \\
\hline Socioeconomic status & -.01 & -.04 \\
\hline \multicolumn{3}{|l|}{ Year in college } \\
\hline Second year (First year) & .05 & $.27 *$ \\
\hline Third year (First year) & $.20^{*}$ & .20 \\
\hline Fourth year (First year) & $.31 * *$ & .08 \\
\hline Fifth year or more (First year) & $.46^{* * *}$ & -.00 \\
\hline Grade point average & -.00 & -.05 \\
\hline \multicolumn{3}{|l|}{ 2. Pre-college cheating behavior } \\
\hline Frequency of high school cheating & $.16^{* * *}$ & -.05 \\
\hline \multicolumn{3}{|l|}{ 3. Co-curricular participation } \\
\hline Fraternity/sorority membership (No) & $.18^{*}$ & .06 \\
\hline Club participation (No) & .10 & .04 \\
\hline \multicolumn{3}{|l|}{ 4. Moral obligation not to cheat } \\
\hline It is wrong...[Factor $]$ & $-.22 * * *$ & $-.21 * * *$ \\
\hline \multicolumn{3}{|l|}{ 5. Attitudes about cheating } \\
\hline Diffusion of responsibility [Factor] & .01 & -.02 \\
\hline Personal responsibility [Factor] & $-.14^{*}$ & -.01 \\
\hline \multicolumn{3}{|l|}{ 6. Evaluation of the costs and benefits of cheating } \\
\hline \multicolumn{3}{|l|}{ Personal pressures } \\
\hline Course load & .09 & -.03 \\
\hline Heavy family responsibility (No) & .06 & -.00 \\
\hline Hours/week spent working & -.00 & .04 \\
\hline \multicolumn{3}{|l|}{ Means for financing education } \\
\hline Scholarship (Pay own way) & $.27 * *$ & .05 \\
\hline Parents (Pay own way) & .09 & -.01 \\
\hline Situational cheating [Factor] & $.29 * * *$ & $.13^{* *}$ \\
\hline \multicolumn{3}{|c|}{ 7. Perceived social pressures to cheat or not to cheat } \\
\hline Prediction of consequence-embarrassment & -.10 & -.09 \\
\hline Deterrent effect-embarrassment & .02 & -.06 \\
\hline \multicolumn{3}{|c|}{ 8. Perceived effectiveness of academic dishonesty policies } \\
\hline Students and faculty understand policies & -.01 & -.11 \\
\hline Faculty support of policies & -.04 & -.12 \\
\hline Academic dishonesty policies deter cheating & -.00 & $.16^{* *}$ \\
\hline \multicolumn{3}{|l|}{ Model statistics } \\
\hline Adjusted $R^{2}$ & .36 & .14 \\
\hline
\end{tabular}

Parentheses indicate reference group for comparison. ${ }^{*} p<.05,{ }^{* *} p<.01, * * * p<.001$. 
as suggested by McCabe (personal communication, April 1, 2002), the results would strongly support our explanation.

The frequency of high school cheating strongly predicted exam cheating but not homework cheating. We propose that frequent high school cheating changes a college student's evaluation of the costs and benefits of cheating by developing skill at cheating without detection (which would both demonstrate the benefit of cheating and reduce the actual risk of detection). Because the benefits of cheating on exams are typically greater than the benefits of cheating on homework in engineering courses, an experienced cheater would be more likely to engage directly in the type of cheating with the highest benefit, cheating on exams. This is consistent with the TPB (Ajzen, 1991).

Similarly, fraternity/sorority membership predicted exam cheating but not homework cheating. We propose that fraternity/sorority membership might allow a group of students to pool their cheating experience in a manner that allows inexperienced cheaters to observe the benefits of cheating and to reduce the actual risk of detection, much like personal cheating experience would, which is consistent with the TPB (Ajzen, 1991).

Students who reported feeling personal responsibility to report and prevent cheating were significantly less likely to report cheating on exams. This seems natural because students who assume more personal responsibility to prevent cheating might well begin their efforts with themselves and be less likely to cheat. By this reasoning we would expect to see a similar relationship for cheating on homework, however, no such relationship was found. We speculate that the wording of questions about personal responsibility focused students' thoughts on the public nature of exam performance versus the private nature of homework activity. For example, two of the questions were worded in the form "If I saw another student cheating, I would ...". It would be unlikely to "see" a cheater in action outside of an exam situation. Thus, these questions may have evoked students' definitions of exam cheating. Multiple researchers have shown that students' definitions of what behaviors constitute cheating vary widely (e.g., Stern and Havlicek, 1986), and our survey respondents classified "cheating" behaviors during exams much more crisply than "cheating" behaviors on homework (Table 1). This may explain why students' personal responsibility for cheating did not have a relationship with homework cheating.

Scholarship students were more likely to cheat on exams than were students who reported paying their own way, but this distinction was not observed for homework cheating. We propose that scholarship students are often under financial pressure to maintain a minimum grade 
point average and that the benefit of achieving a higher grade on an exam is much greater than the benefit of achieving a higher grade on a homework assignment in typical engineering classes. Thus, scholarship students would not be likely to see a benefit to cheating on homework when they evaluate the costs and benefits of cheating, which is consistent with the TPB (Ajzen, 1991).

The deterrent effect of academic dishonesty policies differentially predicted cheating on exams and homework. Counterintuitively, students who agreed that "academic dishonesty policies at your institution deter cheating" were more likely to report cheating on homework. We speculate that students feel that enforced academic dishonesty policies would deter their cheating; however, in the absence of enforced policies, they do cheat on types of assessments for which policies are least defined and enforced, such as homework. Responses to a question on the survey that was not included in our models indicate that students feel that academic dishonesty policies are not enforced at their institutions (In this sample, when answering the question "Do faculty support the academic dishonesty policies of your institution?", $48.8 \%$ answered either "not at all" or "somewhat"). Implicit policies on exam cheating, and their occasional enforcement, may explain why this effect is seen for homework cheating but not exam cheating.

\section{Unilateral Deterrents to Cheating: Moral Obligation and Situational Cheating}

Two factors showed a strong deterrent effect to cheating in both types of assessment: moral obligation not to cheat and situational cheating. The moral obligation not to cheat had the most explanatory power of any block of variables in the regression models, significantly explaining $16 \%$ of the variance in cheating on exams and $9 \%$ of the variance in cheating on homework. (Note that these percentages are much larger than the 3\% of the variance in Beck and Ajzen's (1991) regression model for cheating.) The percentages of the variance explained by moral obligation in our models strongly support Beck and Ajzen's proposal that moral obligation plays an important role in the TPB for dishonest acts. Specifically, a student's agreement that "It is wrong to cheat even if [difficult circumstance]..." is strongly negatively correlated with both the "frequency of cheating on exams" and "the frequency of cheating on homework". Looking at this result conversely, students who disagreed with these statements "recognize and accept cheating as an undesirable behavior; however, its occurrence can be excused in certain instances" (Haines, Diekhoff, LaBeff, and Clark, 1986, p. 353). This 
attitude, called neutralization, has been found to be an important influence on college students' cheating behavior (e.g., Haines et al., 1986; Liska, 1978). Our results also support this finding.

Student agreement with statements that "I would cheat...[if it helped me alleviate a stressful situation]" is positively correlated with the frequency of cheating on both types of assessment. This is a logical result because stressful situations that might be alleviated by (undetected) cheating could be alleviated by cheating on any type of assessment.

\section{Summary}

Our major finding is that correlates of cheating vary by type of assessment. This finding is consistent with several aspects of previous work, notably: (1) the TPB (Ajzen, 1991) which implies that each construct that contributes to actual behavior will vary by situation; (2) differences in prevalence of cheating by type of assessment (e.g., Baird, 1980; Bowers, 1964; Brown, 1996; Diekhoff et al., 1996; Hanson, 1990; Jensen et al., 2002; McCabe, 1997; Michaels and Miethe, 1989; Stearns, 2001; Storch and Storch, 2002; data from McCabe's 1993 study reported in Whitley and Keith-Spiegel, 2002); (3) differences identified in the relationships in four different path models for four different cheating situations (Pratt and McLaughlin, 1989); (4) concerns about the common practice in cheating research of combining cheating behaviors for different types of assessments (Crown and Spiller, 1998; Thorpe et al., 1999; Whitley, 1998); (5) published difficulties in creating general definitions for cheating and academic dishonesty without specifying situations and behaviors (e.g., Ratner, 1996), and (6) published classifications of cheating behaviors by type of assessment for practical applications of cheating research, such as prevention and detection, policy, working definitions, and strategies for teachers who must deal with academic dishonesty (Cizek, 1999; Lipson and McGavern, 1993; Whitley and Keith-Spiegel, 2002). Future research on cheating should carefully distinguish between behaviors on different types of assessment.

Our secondary findings are that a student's conviction that cheating is wrong no matter what the circumstances is a strong deterrent to cheating across types of assessment and that a student who agrees that he or she would cheat in order to alleviate stressful situations is more likely to cheat on exams and on homework. Future research on cheating should explore students' moral obligation not to cheat and their moral development. 


\section{LIMITATIONS}

The sample of convenience is not necessarily representative of the engineering students on any single campus or of the types of institutions involved. The sample of convenience also created a situation in which records that would enable the calculation of response rates were not kept. If our survey had been designed based on the TPB, a fuller complement of variables would have addressed the TPB constructs of subjective norms and perceived behavioral control.

\section{CONCLUSIONS AND IMPLICATIONS}

Since the 1960 's, upwards of $80 \%$ of U.S. undergraduates report that they have cheated during college, although rates vary by college major. Yet the severity of the cheating is increasing: "for example, students admitting to copying from another student on an examination doubled from $26 \%$ to $52 \%$ between 1963 and 1993" (McCabe, 1997, p. 435). The prevalence and increasing severity of cheating should be distressing to educators because of their implications for: (1) undermining institutional missions that include preparation for citizenship and service to society, each of which has a moral dimension (King and Mayhew, 2002; Whitley and Keith-Spiegel, 2002); (2) invalidating measures of student learning and grading equity (Whitley and Keith-Spiegel, 2002); (3) damaging student and faculty morale, the reputation of the institution, and public confidence in higher education (Whitley and Keith-Spiegel, 2002); and (4) increasing the likelihood of engagement in dishonest acts both outside the classroom and after graduation (e.g., Baldwin et al., 1996; Beck and Ajzen, 1991; Nonis and Swift, 2001). These four implications of the prevalence and severity of cheating have inspired a substantial body of research on cheating among college students, including eleven review articles published since 1977 (Brown and Emmett, 2001; Bushway and Nash, 1977; Cizek, 1999; Cole and McCabe, 1996; Crown and Spiller, 1998; Dowd, 1992; Kibler, 1993; McCabe et al., 2001; Whitley, 1998; Whitley and Keith-Spiegel, 2002; Whitley et al., 1999).

Our study fills several gaps in the existing literature on student cheating. Separate models for cheating behavior are made for two types of assessment, exams and homework. Both the careful distinction between the types of assessment and also the distinct study of homework are rare contributions to research on cheating. Also, our sample of engineering undergraduates is an important contribution because engineering students self-report higher frequencies of cheating than all other majors except for business majors (e.g., McCabe, 1997), yet only two multi-institutional 
studies of cheating other than our own have specifically identified engineering students (Bowers, 1964; McCabe, 1997). The importance of studying cheating among engineering undergraduates is heightened by nationwide emphases among engineering faculty on assessing student learning outcomes and explicitly teaching professional ethics. Both of these emphases were codified in changes to the nationwide accreditation requirements for engineering programs (Moore, 1996).

In this study, we found that students don't see cheating as a single construct and their decisions to cheat or not to cheat are influenced differently depending on the type of assessment. Therefore, faculty and administrators should carefully define for students what does and does not constitute cheating for each type of assessment, such as exams, homework, term papers, projects, laboratory reports, and oral presentations. Explicit definitions of "cheating" seem especially appropriate because of the recent emphasis on collaborative learning, which communicates to students that working together is often encouraged by faculty.

In addition, we found that a student's conviction that cheating is wrong no matter what the circumstances is a deterrent to cheating across types of assessment and that a student who agrees that they would cheat in order to alleviate stressful situations is more likely to cheat on exams and on homework. Thus, interventions that develop student understanding that cheating is wrong could deter all forms of cheating, if clear definitions of cheating are communicated to students.

Our findings have two implications for future research on cheating. First, future research on cheating should carefully word each behavior as specifically for one type of assessment. Second, future research should explore students' moral obligation not to cheat and their moral development.

\section{ACKNOWLEDGMENTS}

We would like to thank Dr. Susan M. Montgomery and Dr. Nicholas H. Steneck for their contributions to the design of the survey; Dr. Eric L. Dey and Dr. Heidi E. Grunwald for their suggestions regarding statistical analysis in exploratory versions of this study; the engineering faculty who distributed the surveys in their classes; and the students who responded. We also gratefully acknowledge the financial support of the University of Michigan College of Engineering and the Educational Research and Methods Division of the American Society for Engineering Education (ASEE). 


\section{END NOTES}

1. We recognize that some cheating may not be planned. For example situations in which cheating might not be planned (such as a student observing, during an exam, that a neighbor's paper is available) see Hetherington and Feldman (1964).

2. Note that "Ajzen" recently changed his name to "Aizen". Armitage and Conner (2001) describe this in a footnoted personal communication dated November 8, 1999.

\section{REFERENCES}

Ajzen, I. (1991). The theory of planned behavior. Organizational Behavior and Human Decision Processes 50: 179-211.

Ajzen, I. (2002). Perceived behavioral control, self-efficacy, locus of control, and the theory of planned behavior. Journal of Applied Social Psychology 32(4): 665-683.

Armitage, C. J., and Conner, M. (2001). Efficacy of the theory of planned behavior: A metaanalytic review. British Journal of Social Psychology 40: 471-499.

Baird, J. S. (1980). Current trends in college cheating. Psychology in the Schools 17(4): 515-222.

Baldwin, D. C., Daugherty, S. R., Rowley, B. D., and Schwartz, M. D. (1996). Cheating in medical school: A survey of second-year students at 31 schools. Academic Medicine 71: 267-273.

Beck, L., and Ajzen, I. (1991). Predicting dishonest actions using the theory of planned behavior. Journal of Research in Personality 25(3): 285-301.

Blankenship, K. L., and Whitley, B. E. (2000). Relation of general deviance to academic dishonesty. Ethics \& Behavior 10(1): 1-12.

Bowers, W. J. (1964). Student Dishonesty and Its Control in College, Bureau of Applied Social Research, Columbia University, New York.

Brown, B. S. (1994). Academic ethics of graduate engineering students. Chemical Engineering Education (Fall 1994), 242-243: 265.

Brown, B. S. (1996). A comparison of the academic ethics of graduate business, education, and engineering students. College Student Journal 30(Sept. '96): 294-301.

Brown, B. S., and Emmett, D. (2001). Explaining the variations in the level of academic dishonesty in studies of college students: some new evidence. College Student Journal 35(4): 529-538.

Buckley, M. R., Wiese, D. S., and Harvey, M. G. (1998). An investigation into the dimensions of unethical behavior. Journal of Education for Business 73(5): 284-290.

Bushway, A., and Nash, W. R. (1977). School cheating behavior. Review of Educational Research 47(4): 623-632.

Carpenter, D. D., Harding, T. S., Montgomery, S. M., and Steneck, N. H. (June 16-19, 2002). P.A.C.E.S.-A study on academic integrity among engineering undergraduates (preliminary conclusions). Proceedings of the 2002 ASEE Annual Conference \& Exposition, Montreal, Quebec.

Carpenter, D. D., Harding, T. S., Montgomery, S. M., Steneck, N. H., and Dey, E. (November 6-9, 2002). Student perceptions of institutional and instructor based techniques for dealing with academic dishonesty. Proceedings of the 32nd ASEE/IEEE Frontiers in Education Conference, Boston, Massachusetts.

Caruana, A., Ramaseshan, B., and Ewing, M. T. (2000). The effect of anomie on academic dishonesty among university students. The International Journal of Educational Management 14(1): 23-30. 


\section{CORRELATES OF CHEATING BY TYPE OF ASSESSMENT}

Cizek, G. J. (1999). Cheating on Tests: How to Do It, Detect It, and Prevent It, Lawrence Erlbaum Associates, Publishers, Mahwah, New Jersey.

Cochran, J. K., Chamlin, M. B., Wood, P. B., and Sellers, C. S. (1999). Shame embarrassment, and formal sanction threats: Extending the deterrence/rational choice model to academic dishonesty. Sociological Inquiry 69(1): 91-105.

Cole, S., and McCabe, D. L. (1996). Issues in academic integrity. New Directions for Student Services 73(Spring 1996): 67-77.

Conner, M., and Armitage, C. J. (1998). Extending the theory of planned behavior: A review and avenues for further research. Journal of Applied Social Psychology 28(15): 1429-1464.

Crown, D. F., and Spiller, M. S. (1998). Learning from the literature on collegiate cheating: A review of empirical research. Journal of Business Ethics 17(6): 683-700.

Diekhoff, G. M., LaBeff, E. E., Clark, R. E., Williams, L. E., Francis, B., and Haines, V. J. (1996). College cheating: Ten years later. Research in Higher Education 37(4): 487-502.

Dowd, S. B. (1992). Academic Integrity-A Review and Case Study. Birmingham, Alabama: School of Health Related Professions-University of Alabama-Birmingham (ERIC Document Reproduction Service No. ED 349060).

Engineering Accreditation Commission. (2004). Criteria for Accrediting Engineering Programs: Effective for Evaluations During the 2004-2005 Accreditation Cycle. Retrieved May 12, 2004, from http://www.abet.org/images/Criteria/E001\%2004-05\%20EAC\%20Criteria\%201120-03.pdf.

Fass, R. A. (1990). Cheating and plagiarism. In: May, W. W. (ed.): Ethics in Higher Education, Macmillan, New York, pp. 170-184.

Finelli, C. J., Harding, T. S., Carpenter, D. D., and Passow, H. J. (June 22-25, 2003). Students' perceptions of both the certainty and the deterrent effect of potential consequences of cheating. Proceedings of the 2003 ASEE Annual Conference and Exposition, Nashville, Tennessee.

Genereux, R. L., and McLeod, B. A. (1995). Circumstances surrounding cheating: A questionnaire study of college students. Research in Higher Education 36(6): 687-704.

Haines, V. J., Diekhoff, G. M., LaBeff, E. E., and Clark, R. E. (1986). College cheating: Immaturity, lack of commitment, and the neutralizing attitude. Research in Higher Education 25(4): $342-354$.

Hanson, A. C. (1990). Academic dishonesty: The impact of student and institutional characteristics on cheating behavior [Abstract] (Doctoral dissertation, University of California, Los Angeles, 1990). Dissertation Abstracts International, 51:89.

Harding, T. S. (2000, October 18-21, 2000). Cheating: Student attitudes and practical approaches to dealing with it. Proceedings of the 30th ASEE/IEEE Frontiers in Education Conference, Kansas City, Missouri.

Harding, T. S. (2001). On the frequency and causes of academic dishonesty among engineering students. Proceedings of the ASEE Annual Conference \& Exposition, Albequerque, NM.

Harding, T. S., Carpenter, D. D., Finelli, C. J., and Passow, H. J. (2003, November 5-8, 2003). An examination of the relationship between academic dishonesty and professional behavior. Proceedings of the 33rd Annual IEEE/ASEE Frontiers in Education Conference, Boulder, Colorado.

Harding, T. S., Carpenter, D. D., Finelli, C. J., and Passow, H. J. (2004). Does academic dishonesty relate to unethical behavior in professional practice? An exploratory study. Science and Engineering Ethics 10(2): 311-324.

Harding, T. S., Carpenter, D. D., Montgomery, S. M., and Steneck, N. H. (October 10-13, 2001). The current state of research on academic dishonesty among engineering students. Proceedings of the 31st ASEE/IEEE Frontiers in Education Conference, Reno, Nevada. 
Harding, T. S., Carpenter, D. D., Montgomery, S. M., and Steneck, N. H. (November 6-9, 2002). A comparison of the role of academic dishonesty policies of several colleges on the cheating behavior of engineering and pre-engineering students. Proceedings of the 32nd ASEE/IEEE Frontiers in Education Conference, Boston, MA.

Harp, J., and Taietz, P. (1966). Academic integrity and social structure: A study of cheating among college students. Social Problems 13(4): 365-373.

Hetherington, E. M., and Feldman, S. E. (1964). College cheating as a function of subject and situational variables. Journal of Educational Psychology 55(4): 212-218.

Hilbert, G. A. (1985). Involvement of nursing students in unethical classroom and clinical behaviors. Journal of Professional Nursing 1: 230-234.

Jackson, C. J., Levine, S. Z., Furnham, A., and Burr, N. (2002). Predictors of cheating behavior at a university: A lesson from the psychology of work. Journal of Applied Social Psychology 32(5): 1031-1046.

Jensen, L. A., Arnett, J. J., Feldman, S. S., and Cauffman, E. (2002). It's wrong, but everybody does it: Academic dishonesty among high school and college students. Contemporary Educational Psychology 27(2): 209-228.

Jordan, A. E. (2001). College student cheating: The role of motivation, perceived norms, attitudes, and knowledge of institutional policy. Ethics \& Behavior 11(3): 233-247.

Kerkvliet, J. (1994). Cheating by economics students: A comparison of survey results. Journal of Economic Education 25(Spring): 121-133.

Kibler, W. L. (1993). Academic dishonesty: A student development dilemma. NASPA Journal 30(4): 252-267.

Kibler, W. L., Nuss, E. M., Paterson, B. G., and Pavela, G. (1988). Academic Integrity and Student Development: Legal Issues and Policy Perspectives, College Administration Publications, Asheville, NC.

King, P. M., and Mayhew, M. J. (2002). Moral judgment development in higher education: Insights from the Defining Issues Test. Journal of Moral Education 31(3): 247-270.

Lanza-Kaduce, L., and Klug, M. (1986). Learning to cheat: The interaction of moraldevelopment and social learning theories. Deviant Behavior 7(3): 243-259.

Lipson, A., and McGavern, N. (May 16-19, 1993). Undergraduate academic dishonesty: A comparison of student, faculty and teaching assistant attitudes and experiences. Paper presented at the 33rd Annual Forum of the Association for Institutional Research, Chicago.

Liska, A. E. (1978). Deviant involvement, associations and attitudes: Specifying the underlying causal structure. Sociology and Social Research 63(1): 73-88.

McCabe, D. L. (1997). Classroom cheating among natural science and engineering majors. Science and Engineering Ethics 3: 433-445.

McCabe, D. L., and Drinan, P. (1999). Toward a culture of academic integrity. Chronicle of Higher Education 46(8): B7.

McCabe, D. L., and Trevino, L. K. (1993). Academic dishonesty: Honor codes and other contextual influences. Journal of Higher Education 64: 522-538.

McCabe, D. L., Trevino, L. K., and Butterfield, K. D. (1996). The influence of collegiate and corporate codes of conduct on ethics-related behavior in the workplace. Business Ethics Quarterly 6(October): 461-476.

McCabe, D. L., Trevino, L. K., and Butterfield, K. D. (1999). Academic integrity in honor code and non-honor code environments: A qualitative investigation. Journal of Higher Education 70(2): 211-234.

McCabe, D. L., Trevino, L. K., and Butterfield, K. D. (2001). Cheating in academic institutions: A decade of research. Ethics \& Behavior 11(3): 219-232.

Michaels, J. W., and Miethe, T. D. (1989). Applying theories of deviance to academic cheating. Social Science Quarterly 70(4): 872-885. 


\section{CORRELATES OF CHEATING BY TYPE OF ASSESSMENT}

Moore, R. E. (1996). Impact of ABET on curriculum content and academic standards. Paper presented at the 1996 98th Annual Meeting and the Ceramic Manufacturing Council's Workshop and Exposition, Indianapolis, Indiana.

National Science Board. (2004). Science and Engineering Indicators 2004 (A Report of the National Science Foundation, Division of Science Resources Statistics). Retrieved May 20, 2004, from http://www.nsf.gov/sbe/srs/seind04/append/c2/at02-22.xls.

Newstead, S. E., Franklyn-Stokes, A., and Armstead, P. (1996). Individual differences in student cheating. Journal of Educational Psychology 88(2): 229-241.

Nonis, S. A., and Swift, C. A. (2001). An examination of the relationship between academic dishonesty and workplace dishonesty: A multicampus investigation. Journal of Education for Business 77(2): 69-77.

Nuss, E. M. (1984). Academic integrity: Comparing faculty and student attitudes. Improving College and University Teaching 32(3): 140-144.

Ogilby, S. M. (1995). The ethics of academic behavior: Will it affect professional behavior? Journal of Education for Business 71(2): 92-96.

Pavela, G. (1978). Judicial review of academic decision-making after Horowitz. School Law Journal 55(8): 55-75.

Pratt, C. B., and McLaughlin, G. W. (1989). An analysis of predictors of college students' ethical inclinations. Research in Higher Education 30(2): 195-219.

Ratner, J. (1996). Academic dishonesty and moral development: Theory revisited. [Abstract] (Doctoral dissertation: Columbia University Teachers College, 1996). Dissertation Abstracts International, 57(07), 2902.

Rawwas, M. Y. A., and Isakson, H. R. (2000). Ethics of tomorrow's business managers: The influence of personal beliefs and values, individual characteristics, and situational factors. Journal of Education for Business, 75(6).

Roberts, P., Anderson, J., and Yanish, P. (October, 1997). Academic misconduct: Where do we start? Paper presented at the Annual Conference of the Northern Rocky Mountain Educational Research Association, Jackson, Wyoming.

Shaughnessy, M. F. (1988). The Psychology of Cheating Behavior, Eastern New Mexico University, Portales, New Mexico(ERIC Document Reproduction Service No. ED 303708).

Sims, R. L. (1993). The relationship between academic dishonesty and unethical business practices. Journal of Education for Business 68(4): 207-211.

Singhal, A. C. (1982). Factors in student dishonesty. Psychological Reports 51: 775-780.

Sisson, E., and Todd-Mancillas, W. R. (March, 1984). Cheating in engineering courses: Shortand long-term consequences. Paper presented at the Annual Meeting of the Midwest Section of the American Society of Engineering Education (ASEE), Wichita, Nebraska (ERIC Document Reproduction Service no. ED 242523).

Spiller, M. S., and Crown, D. F. (1995). Changes over time in academic dishonesty and unethical business practices. Journal of Education for Business 68(4): 207-211.

Stark, J. S., and Lattucca, L. R. (1997). Shaping the College Curriculum: Academic Plans in Action, Allyn and Bacon, Boston.

Stearns, S. A. (2001). The student-instructor relationship's effect on academic integrity. Ethics \& Behavior 11(3): 275-285.

Stern, E. B., and Havlicek, L. (1986). Academic misconduct: Results of faculty and undergraduate student surveys. Journal of Allied Health 15(2): 129-142.

Storch, E. A., and Storch, J. B. (2002). Fraternities, sororities, and academic dishonesty. College Student Journal 36(2): 247-252.

Sudman, S., and Bradburn, N. M. (1982). Asking Questions, Jossey-Bass, San Francisco.

Tang, S., and Zuo, J. (1997). Profile of college examination cheaters. College Student Journal 31: 340-346. 
Thorpe, M. F., Pittenger, D. J., and Reed, B. D. (1999). Cheating the researcher: A study of the relation between personality measures and self-reported cheating. College Student Journal 33(1): 49-59.

Tibbetts, S. G. (1997). College student perceptions of utility and intentions of test cheating (Academic dishonesty) [Abstract] (Doctoral dissertation: University of Maryland College Park, 1997). Dissertation Abstracts International, 58(06A), 2400.

Todd-Mancillas, W. R. (1987). Academic dishonesty among communication students and professionals: Some consequences and what might be done about them. Paper presented at the Annual Meeting of the Speech Communication Association, Boston.

Whitley, B. E. (1998). Factors associated with cheating among college students: A review. Research in Higher Education 39(3): 235-274.

Whitley, B. E., and Keith-Spiegel, P. (2002). Academic Dishonesty: An Educator's Guide, Lawrence Erlbaum Associates, Publishers, Mahwah, NJ.

Whitley, B. E., and Kost, C. R. (1999). College students' perceptions of peers who cheat. Journal of Applied Social Psychology 29(8): 1732-1760.

Whitley, B. E., Nelson, A. B., and Jones, C. J. (1999). Gender differences in cheating attitudes and classroom cheating behavior: A meta-analysis. Sex Roles 41(9-10): 657-680.

Received February 22, 2005. 